\title{
HOMENAGEM.
}

\section{No centenário de Rui Barbosa e cinquentenário da Oração aos Moços *.}

\author{
Ataliba Nogueira \\ Professor emérito na Faculdade de Direito \\ da Universidade de São Paulo.
}

Na opulenta biblioteca de José Carlos de Macedo Soares, que aliás não escapou à ironia de Agripino Grieco, duas estantes se defrontavam. Foram assim dispostas para o cotejo da produção literária do mais fecundo escritor português com as obras do incansável escritor brasileiro.

Não havia repetição de edições nem de Camilo Castelo Branco nem de Rui Barbosa. Só a primeira edição de cada obra. Em outras estantes, o capricho de colecionar alinhava todas as edições dos trabalhos de um e outro, mesmo as espúrias.

Comprazia-se o saudoso antigo presidente da Academia Brasileira de Letras em salientar como o autor brasileiro ultrapassara em muito o genial Camilo.

As suas obras completas, em curso de publicação pela Casa de Rui Barbosa, irão além de trezentos volumes em formato grande.

Pois bem, a maior parte dos seus escritos são discursos ou trabalhos de gênero análogo proferidos na tribuna parlamentar, em conferências internacionais, universidades, insti-

\footnotetext{
* Oração proferida na sessão solene comemorativa do centenário de RUI BARBOSA e cinquentenário da Oração aos Moços, realizada aos 29 de março de 1971, no salão nobre desta Faculdade.
} 
tutos jurídicos, academias de letras, em manifestações à sua pessoa, nos comícios políticos, quer nos teatros quer na praça pública e no pretório mais alto do Brasil.

Dissemos que tais peças concionatórias foram proferidas nos lugares adequados, mas justamente a que nos reune hoje para lhe comemorar o meio centenário, a Oração aos moços, não foi por êle proferida nesta Faculdade de Direito.

Principia por estas palavras: "Não quis Deus que os meus cinquienta anos de consagração ao direito viessem receber no templo do seu ensino em São Paulo o sêlo de uma grande benção".

Escritos forenses, artigos de imprensa, peças exclusivamente literárias perdem-se na mole dos discursos e conferências.

E por excelência orador.

Por tal motivo é que o antigo professor desta casa, José Augusto César, de saudosa memória, de vasta cultura histórica e jurídica, aproximou Cícero e Rui Barbosa. Colocou-os ambos defronte um do outro, não pelo acervo de suas obras, em comparação meramente física, mas traçando o paralelo de de duas vidas, de duas missões apostolares, de dois juristas, dois escritores, dois oradores, dois gênios.

Houve quem não apreciasse a confrontação das figuras históricas. E que não reparára na difícil tarefa de quem se propõe fazer comparações. Terá que afirmar os pontos de semelhança, de aproximar épocas diversas, de descobrir diferenças, de ressaltar a superioridade ora de um ora de outro, de esbater os defeitos de ambos. Ao admirador cego e apaixonado não lhe é suportável, no cotejo, ver uma que outra vez o seu ídolo colocado em segundo plano. São os escolhos do paralelo.

Em tal gênero não se sairam sempre bem, nem o arguto 
Plutarco nas Vidas paralelas, nem o solerte Antonio Feliciano de Castilho na penetrante comparação entre Vieira e Bernardes.

O leitor atento não aceita todas as conclusões da longa exposição do professor José Augusto César, mas dá plena razão à maioria das aproximações entre os dois vultos da humanidade, Cícero e Rui.

A sua é obra histórica e também culta análise literária, somente possível a quem conhecesse a vida, os feitos e os trabalhos de ambos, mas ainda demonstra ser senhor de crítica sagaz e asseńtado espírito de justiça.

Cícero e Rui. "Há entre os dois analogias acentuadas: ambos advogados eminentes, sempre empenhados em defender os oprimidos contra as violências do poder; ambos políticos versáteis, mas amando no fundo a justiça e a liberdade; ambos grandes escritores, igualmente enamorados da forma literária; ambos polígrafos eruditos; ambos, com Emílio Castelar, os maiores oradores não-eclesiásticos da raça latina"

"Onde Rui e Cícero podem ser perfeitamente comparados - diz Augusto César - é no ardor e talento com que defenderam a lei e a liberdade contra os excessos do poder e das facções populares durante as terríveis comoções que assinalaram em Roma os últimos tempos da república e aqui se seguiram à queda do império."

O governo despótico de Sylla em Roma revela o ardoroso tribuno Cícero. Situação idêntica no Brasil descobre um novo Rui, pois não era aquele Rui conhecido até então. Um dos discursos mais vibrantes de toda a sua vida profere-o diante do Supremo Tribunal Federal. "Naqueles transes, disse ele mais tarde, houve lágrimas entre fortes"

"Naquele corpo pequeno e débil habitava a alma de herói. Suportou o exílio com muito mais firmeza e dignidade do que Cícero." 
"A qualidade dominante de ambos foi o gênio literário. Foram primacialmente oradores e escritores.... Nenhum dos dois amava a concisão, a sobriedade elegante de Demóstenes; ambos preferiam os longos períodos sonoros, a amplidão da frase, as altas figuras pomposas."

Há, porém, dificuldade de comparação rigorosa. $\mathrm{O}$ gosto iiterário do tempo de Cícero não é o mesmo da época de Rui, como o da quadra de Rui não é o nosso. Cada qual em sua época.

Pode divergir-se do seu estilo, mas uma coisa é certa: mesmo discorrendo sobre os temas mais comuns, o seu estilo é sem vulgaridade.

Relembrando de novo o paralelo entre ambos os gigantes, recordo a afirmação do professor Augusto César: "Para o Brasil não é por certo pequena a glória de poder colocar um seu filho ao lado de Cícero, como encarnação igualmente elevada da cultura latina. Como Cícero, Rui pertence à assembléia imortal dos maiores artistas da humanidade. Um grande discurso de Rui é como um quadro de Rafael, uma estátua de Miguel Angelo, um poema de Goethe, superior realização do belo"

"Com Cícero, Rui faz parte dessa linhagem de advogados do direito e da liberdade, que ele mesmo celebrou numa das suas orações mais memoráveis."

\section{Senhores,}

Aos bacharelandos de 1920 somos todos devedores dessa forte e ao mesmo tempo graciosa peça literária por eles mesmos denominada Oração aos moços.

Depois das comemorações triunfais do seu cinqüentenário político, em agosto de 1918, com os empolgantes discur- 
sos da missa campal e da Biblioteca Nacional, sentia-se Rui abatido pela derrota na sua quarta candidatura à presidência da república.

A primeira, em 1905, levantada pela sua estremecida Bahia, recusa-a em favor de Afonso Pena. A segunda, em 19091910, dá-lhe apenas o consolo de ser o centro e o motor da maior campanha civilista que já houve no Brasil. A terceira, em julho de 1913, termina com o seu Manifesto à Nação, de 28 de dezembro, em que a renuncia.

Assim mesmo, recusa altas missões como a de representante na Liga das Nações para, septuagenário, ir percorrer o sertão da Bahia, em batalha eleitoral.

Vendo sofrer o seu estado com a intervenção federal, recusa outros convites honrosos vindos do governo e de modo espetacular renuncia à cadeira de senador.

Neste clima político e neste emaranhado de casos pessoais é que recebe o convite dos bacharelandos da nossa querida Faculdade de Direito e aceita-o. Não viria ler o discurso, mas escreve-o, salientando assim comemorar o seu jubileu jurídico, pois meio século antes aqui mesmo recebera o grau de bacharel. E é nosso professor honorário.

Precisamente no dia de hoje, decorridos dez lustros, são lidas as suas palavras diante deste mesmo busto de bronze sobre um terço de coluna dórica, repousado no recanto mais nobre deste salão.

Ao contrário do que se esperava, as suas palavras não são de combate, nem de objugatória, nem de azedume ou ressentimento, nem mesmo de queixume ou lamentação. Conseqüentemente, nelas não há ódio ou vindicta. Não é queimoso.

É o milagre da ação dos moços acadêmicos. Em primeiro lugar, no recesso do seu gabinete, cercado pelo oceano de livros, a mocidade tinha-o levado a transportar-se para cin- 
quienta anos atrás. E êle via os jovens. Depois, considerou bem no convite.

A mocidade queria a sua palavra de mestre, naquele momento solene de iniciar a vida pública e profissional. Deixou o paraninfo tudo quanto era pessoal para iluminar-lhe o caminho. Ou melhor, do que lhe era pessoal Rui só recorda aos rapazes as lições da sua longa experiência nos variados campos da própria atividade. É um Rui algo diferente.

E é um Rui ansioso para que os jovens levem por diante o que ele entrevia de reformas radicais no mundo de após guerra. Até então só havia ideais, quanta vez só pressentidos vagamente. Já agora eram realidades que colocavam problemas à argúcia, à competência e tenacidade da juventude. Os velhos em geral não podiam compreendê-los. E que os não compreendiam ou os não aceitavam, a prova estava na frieza e até desprêzo com que foram recebidos o seu programa de revisão da constituição federal, adotado pelo Partido Republicano Liberal, e sobretudo as afirmações sociais, em substituição às liberais, do maior monumento que deixou escrito da nova campanha presidencial.

Dois anos antes da Oração aos moços, a 20 de março de 1919, profere a conferência inserta na edição da Livraria Catilina, da cidade do Salvador, sob o título A questão social e política no Brasil. Pronunciou-a no Teatro lírico do Rio de Janeiro.

Entra em cheio no assunto principal: O trabalho. Recorda com emoção os seus tempos de acadêmico de direito em São Paulo. Foi aqui que se estreiou na tribuna popular, na primeira conferência abolicionista que se ousou proferir na província. E à sua palavra aliou-se a sua pena para a propaganda da abolição do trabalho escravo. Com ele formam em grande número os acadêmicos, principalmente os poetas. Castro Alves continua os temas de Paulo Eiró. O movimento era contra os seus próprios interesses, porque feria os dos seus pais. 
Rui nem sequer pôde ir a Campinas para visitar seu primo, o conselheiro Albino Barbosa de Oliveira, na sua fazenda do Rio das Pedras. Entre as cartas recebidas pelos estudantes mais de uma dizia: "Você está ai estudando o direito e não aprendeu que seu pai tem direito à propriedade dos escravos?" Outra lembrava: "É com o produto do trabalho escravo que você estuda e, depois de formado, irá à Europa"

Quem participou daquela campanha virulenta e eficiente, utilizando-se de clubes então existentes, que os estudantes tomavam para si, desviando-os da sua finalidade, como Rui narra no discurso da campanha civilista, lido nesta mesma $\mathrm{Fa}$ culdade, em 1909 (pág. 122); quem tinha aquele passado, não podia ser indiferente à justiça social que reclamava minudente legislação do trabalho. E os demais temas sociais que Rui se propunha tornar realidade, se fosse eleito para a presidência da república. A este esboço denomina a segunda emancipação. É preciso e conciso quando se ocupa do que denomina "Os abolicionistas e os operários", "Abolicionismo e reforma social", "Casas de operários", "Trabalho de menores", "Horas de trabalho", "Higiene", "As mães operárias", "Acidentes no trabalho", "O seguro operário", "Trabalho e idade", "Duração do trabalho", "Trabalho noturno", "Gravic'ez e parto", "Armazem de vendas aos operários", "O capital e o trabalho"

Afirma Rui que tais temas programaticos de justiça social ele os foi buscar na Igreja católica e se confessa discípulo do grande e heroico cardeal Mercier, arcebispo de Malines, dos homens mais respeitáveis do mundo de então.

$\mathrm{E}$ assim que se compreende porque os jovens querem para paraninfo e desejam para lhes aconselhar e abrir horizontes novos um septuagenário. Com quase 72 anos de idade, é o estudioso, é o jurista culto, o político experimentado que pensa e medita os problemas capitais do seu tempo, olhos postos no futuro. 
A Oração aos moços, depois de longa introdução, principia realmente quando o orador desenvolve o seu primeiro argumento, fruto da experiência não só dos anos, mas das situações e comércio com os homens e parte magna em acontecimentos e posições que ele, melhor que outros, soube aproveitar.

Eis o seu início: "Oração e trabalho são os recursos mais poderosos na criação moral do homem. A oração é o íntimo sublimar-se d'alma pelo contacto com Deus. O trabalho é o inteirar, o desenvolver, o apurar das energias do corpo e do espírito, mediante a ação contínua de cada um sobre o mundo onde habitamos"

"O indivíduo que trabalha acerca-se continuadamente do autor de todas as coisas, tomando na sua obra uma parte, de que depende também a dele. O Criador começa, e a criatura acaba a criação de si própria."

"Quem quer, pois, que trabalhe, está em oração ao Senhor" (págs. 33 a 34)

A seguir Rui afirma que ao intelectual o maior trabalho é estudar. Mas, estudar não é somente ler. "Os que madrugam no ler, convém madrugarem também no pensar. Vulgar é o ler, raro o refletir. O saber não está na ciência alheia que se absorve, mas principalmente nas idéias próprias, que se geram dos conhecimentos absorvidos, mediante a trasmutação por que passam, no espírito que os assimila (pág. 46) E Rui remata com agudeza: "Um sabedor não é armário de sabedoria armazenada, mas transformador reflexivo de aquisições digeridas" (ibidem)

São de absoluta precisão e perspicácia os conselhos do paraninfo aos jovens bacharéis que elegem seja a advocacia (como ele próprio elegeu) seja a magistratura. Derrama-se em elogios a uma e outra. Salienta-lhes o quanto têm de nobres. E castiga com aspereza aquele que as deturpa e envilece. 
E como ambas as profissões se agitam em busca da justiça, Rui a juízes e advogados adverte, como um dia já recordara a políticos e legisladores: "Não há justiça onde não haja Deus. Quereríeis que vo-lo demonstrasse? Mas seria perder tempo, se já não encontrastes a demonstração no espetáculo atual da terra, na catástrofe da humanidade. O gênero humano afundiu-se na matéria, e no oceano violento da matéria flutuam hoje os destroços da civilização meio destruida"

"Esse fatal excídio está clamando por Deus. Quando ele tornar a nós, as nações abandonarão a guerra, e a paz então assomará entre elas, a paz das leis e da justiça, que o mundo ainda não tem, por que ainda não crê" (pág. 75)

\section{Senhores,}

$€$ impressionante a imperiosa afirmação daquele mestre a quem tanto admiramos, quando nos aponta Deus.

Não é somente neste passo que ele o invoca tão peremptoriamente. A Oração aos moços principia e termina com o nome de Deus. De começo ao fim contei 42 vezes o nome de Deus na oração do paraninfo.

Rui não chegou a tão grave e firme conclusão, se não por processo lento, seja de observação, de experiência, de reflexão, seja porque sentiu de fato o sobrenatural. A sua fé agora é robusta. Não é crente por hereditariedade.

Recordemos a sua vida. Desde que Rui se libertou da nefasta influência de Saldanha Marinho (1895), amou mais veraz e intensamente a liberdade. Imagino como deve ter sofrido ao defrontar-se com os positivistas da constituinte de 91 e os positivista do governo. Eles, os discipulos de Augusto Comte, a lhe darem lições de liberdade, quando Rui, eivado de preconceitos, oprimia a liberdade. 
Já nesse instante os contactos com D. Antonio de Macedo Costa lhe trazem os primeiros casos de consciência.

Desperta o grande Rui, porém, somente quando sofre as agruras, as aperturas e os sofrimentos do exílio. Passa-o quase todo na Inglaterra. O seu espírito atento é despertado pelas atividades intelectuais de eminente político, da sua mesma idade, ministro do governo inglês e pouco mais tarde primeiro ministro da Inglaterra, lord Balfour.

Acompanhando o trabalho ingente do gabinete e especialmente o de lord Balfour, Rui é surpreendido pelo afinco com que o grande estadista estuda os assuntos de religião e dá à estampa, em 1895, um livro sobre os Fundamentos da fé.

Compreendeu toda a seriedade da obra e a sua base irrespondível.

Podia ele dai por diante falar de Deus e o fez a meúde, maximé no discurso do colégio Anchieta a seu filho e demais bacharéis em letras; na missa campal de seu jubileu cívico; na Oração aos moços, aos bacharéis da nossa Faculdade de Direito.

Contemporâneo de Rui também foi o maior negador da divindade, Nietzsche. Em páginas dramáticas anunciou a morte de Deus, em 1882. Não há, pois, novidade nos que hoje afirmam que Deus morreu.

Uma coisa é certa, hoje mais que àquele tempo: Deus não morreu; "foi o esplendor da divindade que se apagou na história do mundo"

E de que jeito e por que?

Certo escritor alinhou as respostas e aqui as repetimos: "a multiplicidade e imperfeição da representação do mesmo Deus; o abuso do seu nome, para tudo e para nada fazendo-o intervir, sem freio de correção e sem pudor, mesmo em coisas e momentos bem humanos - bem demasiado humanos - de 
opressão do homem pelo homem; a ligação histórica da sua realidade ou da sua invocação a estruturas sociais que, embora de caráter transitório, pareciam participar da eternidade imóvel da própria essência divina; a suspeita, alimentada por uma perspectiva de convergências, de que a idéia de Deus outra coisa não era senão a projeção, em espaço ideal e portanto falso, dos sonhos, desejos, tendências, aspirações e instintos deste animal, entre todos symbolicum, que é o homem; a revolta contra toda realidade - e até contra toda aparência - do princípio de heteronomia; a indiferença" que fez cair no coração humano "o amortecedor dos tranquilizantes" e a resposta às interrogações da inteligência de que as únicas certezas são as certezas naturais (Felipe Bívar, in Broteria, Lisboa, novembro, 1969, pág. 436)

Importa, pois, "purificar a imagem ou representação que nós nos fazemos de Deus. E falar de Deus o menos indignamente possível. Nunca poderemos dizer como Elle é, ou Deus deixaria de ser Deus ou nós deixaríamos de ser homens" (pág. 437)

Rui, referindo-se a Deus por mais de quatro dezenas de vezes, na "Oração aos moços, era sem dúvida movido pela experiência, não por abstrações e dogmatismo. Foi ele próprio que anunciou que falaria aos seus jovens afilhados com base na sua experiência pessoal.

"Essa experiência possibilitará nova consciência da necessidade de Deus; necessidade vital para se viver mais humanamente; necessidade histórica para que o curso do mundo, mais visível e claramente polarizado pela idéia de Deus, adquira novo sentido de história verdadeiramente universal" (pág. 438)

$\mathrm{Na}$ aridez trágica e muda, quando tudo nos parece vazio e sem consistência, o desespero, o pavor do futuro, é arredado ao confiarmos em Deus.

Foi grande a lição do mestre na Oração aos moços. 
Mas, não só aí. Em quase todas as suas páginas, em sua longa vida, há sempre o que aprender, meditar e aproveitar.

Lamentavelmente Rui nunca foi suficientemente lido. Disse-me o livreiro-editor Castilho, em 1949, que a maioria dos seus trabalhos, fossem de que natureza fossem, só tiveram edições reduzidas. Até de trezentos exemplares varias delas! A própria primeira edição da Oração aos moços, seguida da segunda depois de dezenas de anos, foi de apenas 3.000 exemplares, graças ao desvelo de três jovens acadêmicos e numa sua revista interessantissima, embora sob os auspícios de Báco. Aliás, tal circunstância em nada diminuiu o valor da publicação nem o entusiasmo dos moços de então, tanto mais que, não obstante os lindos cachos de uva, o seu nome grego, Dyonisos, emprestava até muita graça.

Rui não acompanhava o movimento editorial, realmente nunca demonstrou interesse na publicação de seus trabalhos. Jornalista de pulso, prestava mais atenção às folhas. Não que desdenhasse o livro, mas queria antes, que fossem publicados tão logo os seus discursos e artigos.

A Oração aos moços lhe constituiu exceção. Diante do entusiasmo dos acadêmicos que lhe levaram as provas, ele as reviu com diligência, corrigindo-as e, por vezes, alterando o texto primitivo.

Quanto dissemos explica a veemência, não digo gratuita, mas sem maior fundamento de certos de seus admiradores apaixonados, que não conhecem a lição do mestre em assuntos da maior importância. Principalmente a ductilidade do espírito de Rui, a sinceridade com que modificava os seus juízos, quando o impunha o amor à verdade.

Preparava cuidadosamente os seus trabalhos, mediante estudo sério e observação inteligente. De outro lado, ele o diz na Oração aos moços, estuda todas as manhãs, desde o surgir do sol e a miúde suas madrugadas o precediam. Por isto, quan- 
ta vez, colhido de surpresa em discursos de colegas senadores, as suas respostas imediatas revelavam o conhecimento de assuntos novos ou a tomada de novas posições devido à cultura posta em dia.

Numa destas situações, depois de responder cumpridamente ao discurso do seu colega, no senado, terminou com estas palavras: "Não me pode arguir o nobre senador: "Esta, só de cabo de esquadra!" Ao que lhe replicou o colega: "Nem seria possível, pois v. ex. se esquece que é general do governo provisório?"

$\mathrm{Na}$ verdade, Rui teve cassada a patente de general, quando exilado, como hoje se cassam os títulos de cidadão concedidos pelas câmaras municipais.

Senhores,

Disse o mestre: "Enquanto as revoluções eram políticas tinham praias que as circundavam, e lhes punham raias visíveis. Depois que se fizeram sociais (e sociais são hoje todas), todas beiram esse Mar Tenebroso, cujo torvo mistério assombra as plagas do mundo contemporâneo"

O seu aviso, em forma de sábia advertência, recebamo-lo com ânimo de não servirmos de estorvo à renovação das instituições políticas e sociais. Ele abriu o caminho. Chegou a elaborar programa para o seu tempo, cinquienta anoș atrás.

Pelo contrário, coloquem-se principalmente os moços na vanguarda. E também Rui quem lhes assinala o lugar, com naturalidade, sem imaginar que as inovações sejam privilégio dos mais idosos.

E se consideramos apostolares as suas lições, porque desdenhá-las?

Que elas sejam do presente, que nada tenham de enve- 
Thecidas neste ano da graça do jubileu do discurso do paraninfo, basta recordar palavra por palavra, período por período, vírgula por vírgula, as últimas páginas da Oração aos moços.

Não nas reproduzo agora, pois devo terminar. Mas, nenhum admirador do grande brasileiro deixe passar este jubileu sem ler as referidas últimas páginas. Ele é que as traçou para remate da oração em que pos toda a sua alma e todo o seu amor à juventude e ao Brasil.

São páginas que não precisam de análise, nem de interpretação, nem de complemento, nem de confronto com outras, nem de guias, nem de inspirações. Ou então, caimos naquilo que já salientamos: Muita admiração, muitos louvores, muita glorificação, muito epiteto altissonante, como águia de Haia e outros, mas nada de ler os seus escritos, os seus discursos, as suas objurgatórias, as suas profecias, digamos assim. Não são do meu agrado - dirão - não são do Rui cuja figura idealizei, cujas proposições deveriam encerrar o meu pensamento e não o de Rui!

Tinha razão o padre Antonio Vieira, o nosso maior orador sacro, quando afirmava: "Não é o bom sermão aquele em que saio contente do pregador, senão aquele em que saio descontente de mim"

Senhores, a Faculdade de Direito, a Academia Paulista de Letras, o Instituto Histórico e Geográfico, o Instituto dos Advogados, que pelos motivos mais variados sempre tributaram o seu preito de admiração a Rui, sentem-se felizes de vir homenagear o mestre mais uma vez. Ao lado dos representantes da turma de bacharelandos, aqui presentes, que propiciaram a fala do paraninfo há meio século, também tributam à memória de Rui Barbosa o seu preito de gratidão pela Oração aos moços ${ }^{1}$

1. O orador recebeu a alta distinção de falar em nome daquelas entidades, respectivamente, da Congregação da Faculdade e dos Presidentes ERNEsto de Morais Leme, Aureliano Leite e Rug de Azgvedo Sodrí 